\title{
How low can dietary greenhouse gas emissions be reduced without impairing nutritional adequacy, affordability and acceptability of the diet? A modelling study to guide sustainable food choices
}

\author{
Marlène Perignon ' $\uparrow$, Gabriel Masset ${ }^{1} \uparrow$, Gaël Ferrari ${ }^{1}$, Tangui Barré ${ }^{1}$, Florent Vieux ${ }^{2}$, \\ Matthieu Maillot ${ }^{2}$, Marie-Josèphe Amiot ${ }^{1}$ and Nicole Darmon ${ }^{1, *}$ \\ ${ }^{1}$ NORT, Aix-Marseille Université, INRA, INSERM, Faculté de Médecine de la Timone, 27 Boulevard Jean Moulin, \\ 13005 Marseille, France: ${ }^{2}$ MS-Nutrition, Marseille, France
}

Submitted 4 September 2015: Final revision received 1 February 2016: Accepted 2 March 2016: First published online 6 April 2016

\begin{abstract}
Objective: To assess the compatibility between reduction of diet-related greenhouse gas emissions (GHGE) and nutritional adequacy, acceptability and affordability dimensions of diet sustainability.

Design: Dietary intake, nutritional composition, GHGE and prices were combined for 402 foods selected among those most consumed by participants of the Individual National Study on Food Consumption. Linear programming was used to model diets with stepwise GHGE reductions, minimized departure from observed diet and three scenarios of nutritional constraints: none (FREE), on macronutrients (MACRO) and for all nutrient recommendations (ADEQ). Nutritional quality was assessed using the mean adequacy ratio (MAR) and solid energy density (SED).

Setting: France.

Subjects: Adults ( $n$ 1899).

Results: In FREE and MACRO scenarios, imposing up to $30 \%$ GHGE reduction did not affect the MAR, SED and food group pattern of the observed diet, but required substitutions within food groups; higher GHGE reductions decreased diet cost, but also nutritional quality, even with constraints on macronutrients. Imposing all nutritional recommendations (ADEQ) increased the fruits and vegetables quantity, reduced SED and slightly increased diet cost without additional modifications induced by the GHGE constraint up to $30 \%$ reduction; higher GHGE reductions decreased diet cost but required non-trivial dietary shifts from the observed diet. Not all the nutritional recommendations could be met for GHGE reductions $\geq 70 \%$.

Conclusions: Moderate GHGE reductions ( $\leq 30 \%)$ were compatible with nutritional adequacy and affordability without adding major food group shifts to those induced by nutritional recommendations. Higher GHGE reductions either impaired nutritional quality, even when macronutrient recommendations were imposed, or required non-trivial dietary shifts compromising acceptability to reach nutritional adequacy.
\end{abstract}

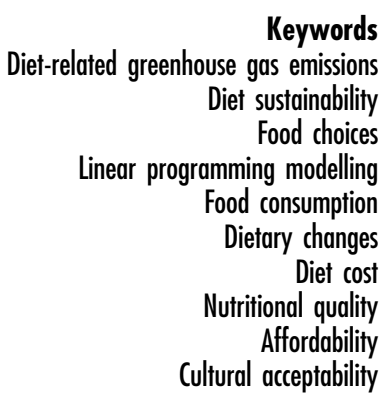

Sustainable diets are defined as nutritionally adequate, safe and healthy, culturally acceptable, financially affordable and with low environmental impacts ${ }^{(1)}$. Reducing emissions arising from the food system is a major lever for achieving greenhouse gas emission (GHGE) reduction targets $^{(2-4)}$. This reduction could be partly achieved through shifts in food consumption since the same

$\dagger$ These authors contributed equally to this work. quantities of different foods emit different levels of greenhouse gas, with livestock products being the largest emitters $^{(5)}$. In the pioneering report How Low Can We Go?, Audsley et al. ${ }^{(6)}$ explored a set of scenarios to reduce UK GHGE by $70 \%$ by 2050 , and suggested that a vegetarian diet or a reduction in livestock product consumption could help meet this target. In parallel, public health authorities recommend consuming plenty of plant-based foods and a moderate amount of animal products, especially red

*Corresponding author: Email nicole.darmon@univ-amu.fr

(C) The Authors 2016. This is an Open Access article, distributed under the terms of the Creative Commons Attribution licence (http:// creativecommons.org/licenses/by/4.0/), which permits unrestricted re-use, distribution, and reproduction in any medium, provided the original 
and processed meats ${ }^{(7)}$. Hence it has been suggested that dietary changes aimed at reducing diet-related GHGE may also promote health ${ }^{(8,9)}$.

Some studies investigating dietary scenarios ${ }^{(10,11)}$ or self-selected diets ${ }^{(12)}$ with reduced meat consumption in the UK have strengthened the message of a compatibility between health and environmental dimensions. However, in a Dutch cohort, the GHGE of usual diets were not associated with mortality, indicating that an environmentally friendlier diet is not necessarily a healthier $\operatorname{diet}^{(13)}$. Other studies showed that higher nutritional quality was associated with higher GHGE in self-selected French $\operatorname{diets}^{(14,15)}$. Thus there is still no consensus on the compatibility between health or nutrition and environmental dimensions.

Affordability is another important dimension of sustainable diets ${ }^{(1)}$. Healthy diets are known to be generally more expensive than unhealthy $\operatorname{diets}^{(16,17)}$, as recently confirmed in studies investigating affordability, healthy dietary pattern and $\mathrm{GHGE}^{(12)}$.

Diet optimization by linear programming has been used in human nutrition to assess the compatibility between nutritional adequacy and affordability of diets, or the gaps in consumption between observed and recommended dietary patterns at population and individual levels ${ }^{(18-21)}$. Linear programming is also a powerful tool to design nutritious diets with a low environmental impact: two studies combined affordability, GHGE reduction and nutritional adequacy in linear programming models ${ }^{(22,23)}$. However, these modelling studies were not based on observed food consumption data, which may compromise the cultural acceptability of the proposed modelled diets.

The main objective of the present study was to assess using diet modelling with linear programming - the compatibility between the reduction of dietary GHGE and the other dimensions of diet sustainability, namely nutritional adequacy, cultural acceptability and affordability. The population's mean observed diet was considered a proxy for a culturally acceptable diet. Thus, to avoid deteriorating the acceptability as much as possible, the models minimized the departure, in terms of food content, from the mean observed diet. The impact of stepwise GHGE reductions on nutritional quality, cost and cultural acceptability of modelled diets was assessed for increasingly stringent levels of nutritional constraints.

\section{Materials and methods}

\section{Population sample and dietary data}

Dietary intakes were derived from the $7 \mathrm{~d}$ food records of a nationally representative stratified random sample of French adults ( $n$ 2624; aged $>18$ years) participating in the Second French Individual and National Study on Food Consumption cross-sectional dietary survey (Étude Individuelle et Nationale sur les Consommations
Alimentaires, INCA2), conducted in 2006-2007 by ANSES (the French agency for food, environmental and occupational health safety) ${ }^{(24)}$. After exclusion of energy under-reporters using Black's equations ${ }^{(25)}$ and individuals consuming hypo-energetic meal substitutes, the present analysis was conducted on a final sample of 1899 adults, aged 47.1 (sD 15.3) years, of whom 1126 were women. The CIQUAL database associated with the survey gives the detailed nutrient composition of all the foods declared to be consumed by the participants (1342 foods and beverages, including water).

\section{Greenhouse gas emissions of foods}

GHGE estimates, expressed in grams of $\mathrm{CO}_{2}$ equivalents

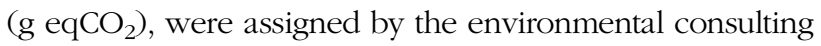
firm Bio by Deloitte (formerly Greenext Service, Paris, France) to 402 foods either selected as being among those most consumed by INCA2 participants, as described by Vieux et al. ${ }^{(14)}$, or identified as having a potential nutritional and/or environmental utility (e.g. soya-based products, some unrefined starchy foods, chestnuts). The GHGE values were assigned based on a hybrid input-output/life cycle assessment (LCA) method using the international ISO 1404x:2006 LCA standards ${ }^{(26,27)}$ and the specific French BP X30-323-0 guidelines ${ }^{(28)}$. The estimates include the whole life cycle of foods, from farm production to usage and waste management of packaging, but exclude emissions arising from indirect land-use change and the highly variable emissions from consumers' transport from retail to home. For composite food items, the LCA analysis considers the GHGE of each ingredient and their proportion in the product, based on the recipes provided by the INCA2 survey. The hybrid approach combined French trade and production data ${ }^{(29,30)}$ and standard life cycle inventory data (e.g. Ecoinvent ${ }^{(31)}$ ) so that the GHGE values assigned reflected the average food products as consumed in the French market ${ }^{(32)}$.

\section{Aggregation of dietary data}

The intakes of the 1342 foods declared to be consumed by INCA2 participants were aggregated into the 402 foods for which GHGE estimates were available, using a nutritional Euclidean distance method developed specifically for the study (see online supplementary material, Supplemental methods, for a full description). Energy and nutrient intakes calculated with the original database of 1342 foods and with the aggregated database of 402 foods are given in Supplemental Table 1.

\section{Diet modelling by linear programming}

Linear programming models were developed to design diets with reduced GHGE and subjected to a set of nutritional constraints, while remaining as close as possible to the mean diet of the French adult population. The impact of the GHGE constraint on food choices, 
Table 1 Constraints in the FREE, MACRO and ADEQ scenarios

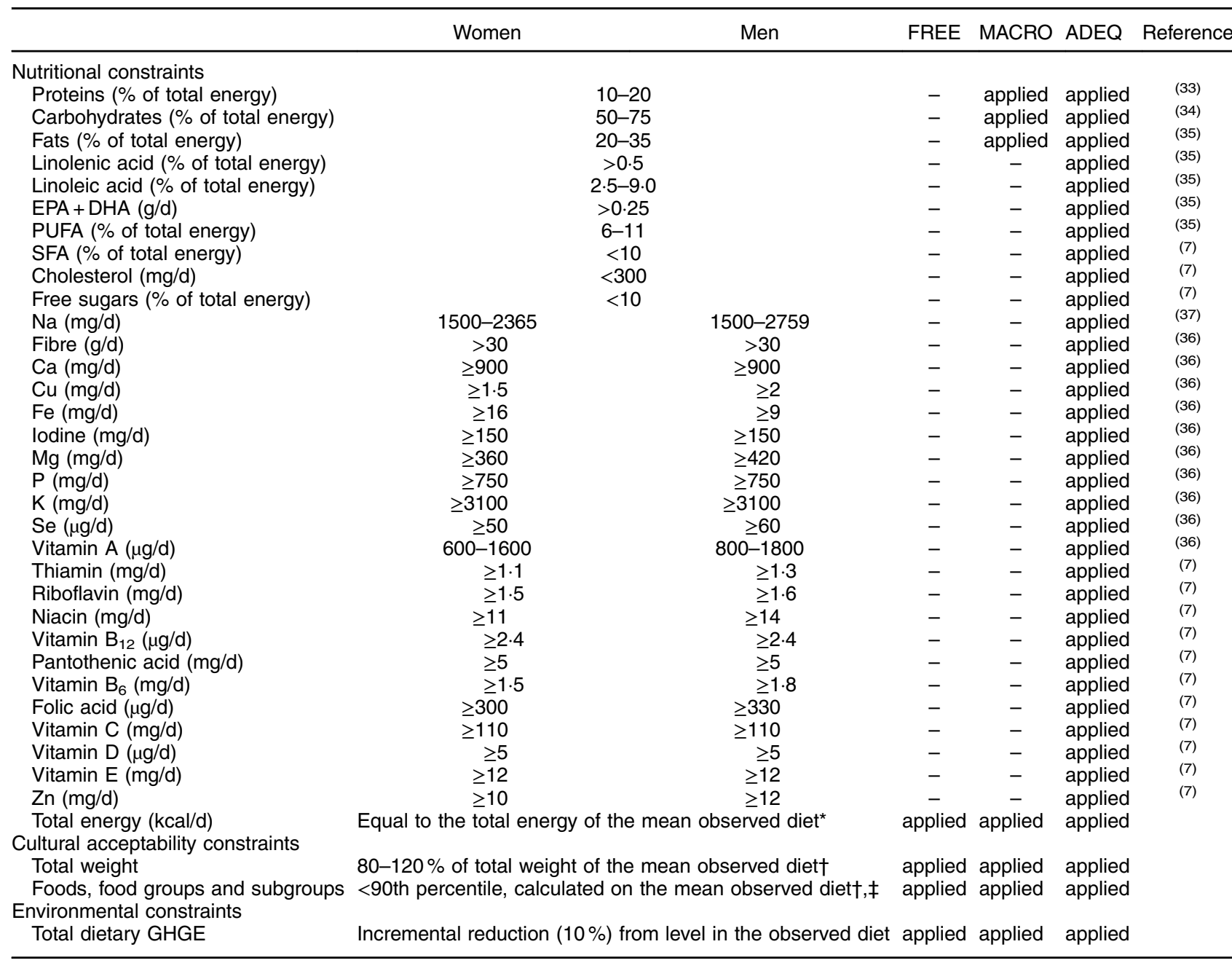

FREE; no nutritional constraints; MACRO, constraints on macronutrients only; ADEQ, constraints on all nutrients; GHGE, greenhouse gas emissions. ${ }^{*} 8109 \mathrm{~kJ} / \mathrm{d}(1938 \mathrm{kcal} / \mathrm{d})$ for women, $10891 \mathrm{~kJ} / \mathrm{d}(2603 \mathrm{kcal} / \mathrm{d})$ for men.

tCalculated for men and women separately.

łFor foods, non-consumers excluded; for food subgroups and groups, non-consumers included.

nutritional quality and cultural acceptability was evaluated by incrementally decreasing diet-related GHGE. Three levels of nutritional exigencies were defined by increasingly stringent nutritional constraints. The cultural acceptability dimension was considered through the objective function by minimizing departure from the mean observed diet. In addition, acceptability constraints on food quantities and energy were used in all models to ensure that the modelled diets remained within the range of diets actually consumed by the general French adult population. All linear programming models were run using the statistical software package SAS version 9.4. The characteristics of the linear programming models (objective function and constraints) are summarized in Table 1.

Nutritional constraints defining the FREE, MACRO and ADEQ scenarios

To assess the compatibility between the imposed reductions of dietary GHGE and nutritional quality of modelled diets, three nutritional scenarios were designed based on increasingly stringent levels of nutritional constraints: (i) no nutritional constraints (FREE scenario); (ii) constraints on macronutrients only (MACRO scenario), in which proteins, total fat and carbohydrates were constrained to minimal and maximal percentages of total energy; and (iii) constraints on all nutrients (ADEQ scenario), in which, in addition to macronutrients, micronutrients, fibre and fatty acids were constrained to a minimal quantity based on the RDA estimated to meet the nutrient needs of $97.5 \%$ of adults in the population and/or a maximal quantity based on recommended upper limits. The values of the nutritional constraints, summarized in Table 1, were derived from WHO recommendations for proteins ${ }^{(7,33)}$, carbohydrates ${ }^{(34)}$, total fat, linoleic acid, $\alpha$-linolenic acid, DHA and EPA, total PUFA $^{(35)}$, cholesterol, SFA and free sugars ${ }^{(7)}$; from the French recommendations for fibre, ten vitamins and nine minerals ${ }^{(36)}$; and from the Nordic Nutrient 
Recommendations for $\mathrm{Na}^{(37)}$. The models were run separately for men and women since observed intakes and nutritional recommendations differ between genders.

Environmental constraint: reductions in greenhouse gas emissions

For each of the three scenarios of nutritional constraints, modelled diets were designed at increasingly stringent levels of GHGE reduction. The constraint imposing the total dietary GHGE reduction was gradually strengthened in $10 \%$ steps, starting from no imposed reduction from the GHGE value of the mean observed diet up to the maximal reduction achievable.

\section{Acceptability constraints}

To avoid unrealistic modelled diets, the total food quantity was constrained to range between $80 \%$ and $120 \%$ of the mean observed intake $(2920 \mathrm{~g} / \mathrm{d}$ for men, $2581 \mathrm{~g} / \mathrm{d}$ for women); the total energy had to be equal to the energy of the mean observed diet (10 916 kJ/d (2609 kcal/d) for men and $8109 \mathrm{~kJ} / \mathrm{d}(1938 \mathrm{kcal} / \mathrm{d})$ for women); and the food item, food group and food subgroup quantities were constrained to be lower than the 90th percentile of the observed intakes. The percentiles were calculated by gender, for consumers only in the case of food items and for the whole population in the case of food groups and subgroups.

\section{Objective function}

In order to translate the objective of remaining as close as possible to the observed diet, the objective function of the linear programming models was defined as the minimization of the total departure between the observed and modelled diets, at both the food item ( $n$ 402) and the food group ( $n$ 8; adapted from the food groups used for the French food-based dietary guidelines ${ }^{(38)}$ : Meat/Fish/Eggs, Dairy Products, Fruit and Vegetables, Starch, Foods High in Fat/Salt/Sugar, Drinks, Seasonings, Mixed Dishes) levels. The objective function was expressed mathematically by:

$$
\begin{aligned}
\text { Minimize } f & =\frac{1}{402} \sum_{i=1}^{402} A B S\left(\frac{Q_{\mathrm{opt}, i}-Q_{\mathrm{obs}, i}}{Q_{\mathrm{obs}, i}}\right) \\
& +\frac{1}{8} \sum_{j=1}^{8} A B S\left(\frac{Q_{\mathrm{opt}, j}-Q_{\mathrm{obs}, j}}{Q_{\mathrm{obs}, j}}\right)
\end{aligned}
$$

where $i$ represents the 402 foods and $j$ the eight food groups, $A B S$ refers to absolute value, $Q_{\text {obs }}$ is the mean observed quantity and $Q_{\text {opt }}$ the optimized quantity.

The absolute function being non-linear, $f$ was then transformed into a linear function, as previously described by Darmon et al. ${ }^{(19)}$, so that linear programming could be applied.

An alternative objective function minimizing the GHGE was used to assess the maximal GHGE reduction achievable for each scenario.

\section{Strength of nutritional constraints}

The dual value, calculated for each nutritional constraint as the improvement in the objective function when the constraint is relaxed by $1 \%$, enabled us to evaluate how restrictive the constraints were and to compare their strength. A non-zero dual value indicated that the corresponding constraint was restrictive, i.e. that fulfilling the constraint had an influence on food selection and thus on deviation from the observed diet. A null dual value indicated that the constraint was not restrictive. The higher the absolute dual value, the more difficult the constraint was to meet.

\section{Nutritional quality assessment}

The mean adequacy ratio (MAR), the mean excess ratio (MER) and the solid energy density (SED) were used to assess the nutritional quality of the observed and modelled diets, as previously described by Vieux et $a l^{(14)}$.

The MAR was calculated for each diet as the mean percentage of daily recommended intakes for twenty key nutrients (proteins, fibre, $\mathrm{Ca}, \mathrm{K}, \mathrm{Fe}, \mathrm{Mg}, \mathrm{Zn}, \mathrm{Cu}$, iodine, Se, vitamin $\mathrm{A}$, vitamin $\mathrm{C}$, vitamin $\mathrm{D}$, vitamin $\mathrm{E}$, thiamin, riboflavin, niacin, vitamin $\mathrm{B}_{6}$, folic acid and vitamin $\mathrm{B}_{12}$ ) by:

$$
\mathrm{MAR}=\frac{1}{20} \sum_{\mathrm{bn}=1}^{20} \frac{Q_{\mathrm{bn}}}{\mathrm{RDA}_{\mathrm{bn}}} \times 100
$$

where $Q_{\mathrm{bn}}$ is the daily quantity of each beneficial nutrient (bn) and $\mathrm{RDA}_{\mathrm{bn}}$ is the corresponding recommended intake for this nutrient. The reference values for the twenty recommended nutrients are given in Table 1 . Each ratio $\left(Q_{\mathrm{bn}} / \mathrm{RDA}_{\mathrm{bn}} \times 100\right)>100$ was set to 100 , so that a high intake of one nutrient could not compensate for the low intake of another ${ }^{(14)}$.

MER was calculated for each diet as the mean daily percentage of the maximum recommended values (MRV) for three nutrients to limit, namely SFA, Na and free sugars, by:

$$
\operatorname{MER}=\left(\frac{1}{3} \sum_{\ln =1}^{3} \frac{Q_{\ln }}{M V_{\ln }} \times 100\right)-100,
$$

where $Q_{\ln }$ is the daily quantity of each nutrient to limit (ln) and $\mathrm{MRV}_{\ln }$ is the corresponding maximum recommended value for this nutrient (Table 1). The term 'free sugars' refers to added sugars plus sugars naturally present in honey, syrups and fruit juices ${ }^{(7)}$. The MRV for SFA and free sugars corresponded to $10 \%$ of the energy of the mean observed diet. The MRV for Na was 2759 and $2365 \mathrm{mg}$ for men and women, respectively, and corresponded to a daily intake of 7 and $6 \mathrm{~g} \mathrm{NaCl}$. Each ratio $\left(Q_{\mathrm{ln}} / \mathrm{MRV}_{\mathrm{ln}} \times 100\right)<100$ was set to 100 , so that a low intake of one harmful nutrient could not compensate for the high intake of another.

The SED, expressed in $\mathrm{kcal} / 100 \mathrm{~g}(1 \mathrm{kcal}=4 \cdot 184 \mathrm{~kJ})$, was calculated as the ratio between energy intake and diet weight. As proposed by Ledikwe et $a l^{(39)}$, only items typically consumed as foods, including soups, were included in the calculation of SED, whereas foods typically 
consumed as beverages, such as milk, juices and other drinks, were excluded.

\section{Acceptability assessment}

The dimension of acceptability was assessed by analysing the changes of quantity $(\mathrm{g} / \mathrm{d})$ occurring for each food group and subgroup, and by calculating the percentage of departure from food quantities in the population's mean observed diet. It was assumed that diets similar, in terms of food composition, to the mean observed diet could be considered as culturally acceptable, with the greatest departure from the observed diet having the highest risk of lower cultural acceptability. The absolute departure was calculated both at the food item level, corresponding to the first term of the objective function, and at the food group level, corresponding to the second term of the objective function.

\section{Diet cost assessment}

Diet cost was estimated based on food prices obtained from the 2006 Kantar Worldpanel purchase database ${ }^{(40)}$, which gives the annual expenditure and the quantity purchased for each food item available on the market in a representative sample of 12000 French households. The mean national prices of the 402 food items were calculated by dividing annual expenditures by the quantities purchased, as previously described by Masset $e t a l .{ }^{(15)}$, and are representative of the most frequently purchased form of each item.

\section{Results}

The GHGE of the mean observed diet were $3667 \mathrm{~g} \mathrm{eqCO}_{2} / \mathrm{d}$ and $4896 \mathrm{~g} \mathrm{eqCO}_{2} / \mathrm{d}$ for women and men, respectively. The maximal GHGE reductions from these observed levels achievable under the constraints were $82.6 \%, 82.2 \%$ and $69.7 \%$ reduction for women, and $81.9 \%, 79.9 \%$ and $74.0 \%$ reduction for men, for the FREE, MACRO and ADEQ scenarios, respectively.

Results of the diets modelled by linear programming are detailed below for women's models only. Results obtained for men's models are presented in the online supplementary material, Supplemental Table 2 and Supplemental Figs 1-3.

\section{Impact of reduction in greenhouse gas emissions on nutritional quality}

The MAR, MER and SED of the observed and modelled diets are presented in Fig. 1(a) to 1(c).

In the mean observed diet, the MAR, MER and SED were $89.9 \%, 20.7 \%$ and $162 \mathrm{kcal} / 100 \mathrm{~g}(678 \mathrm{~kJ} / 100 \mathrm{~g})$, respectively. Thirteen nutrients had a content below $100 \%$ of the RDA, with fibre, vitamin $\mathrm{D}$ and Fe contents in particular covering less than $80 \%$ of the RDA (Table 2). SFA and Na contents exceeded the recommended upper limits.

In the FREE scenario, the MAR and SED of the modelled diets remained similar to those of the mean observed diet for moderate GHGE reductions $(\leq 30 \%)$. Strengthening the GHGE constraint for reductions higher than $30 \%$ induced a progressive decrease in the MAR and an increase in the SED.

In the MACRO scenario, adding constraints on macronutrients with no imposed reduction of GHGE did not affect the MAR or SED, but increased the MER, when compared with the mean observed diet. When imposing the GHGE constraint, the modelled diets had a similar MAR and SED as in the FREE scenario, whatever the GHGE reductions. For moderate GHGE reductions $(\leq 30 \%)$, the MER of MACRO models were higher than for diets modelled under the FREE scenario (Fig. 1(b)). Strengthening the GHGE reduction tended to reduce the MER.

In the ADEQ scenario, the nutritional constraints ensured that the MAR reached $100 \%$ and the MER $0 \%$. The nutritional constraints also induced a reduction of SED compared with both the observed diet and the diets modelled under the FREE and MACRO scenarios. This reduction of the SED reflects an increase in total diet weight induced by the set of nutritional constraints. Imposing GHGE reductions up to $30 \%$ did not induce any additional modifications of the SED, but higher GHGE reductions required decreasing the total diet weight, and thus increasing the SED.

\section{Impact of reduction in greenhouse gas emissions on diet composition}

The food group quantities of each modelled diet are presented in Fig. 2. In the FREE and MACRO scenarios (Fig. 2(a) and 2(b)), food group quantities did not deviate from those of the mean observed diet for moderate GHGE reductions $(\leq 30 \%)$. Reductions ranging from 30 to $60 \%$ induced a progressive decrease in the Meat/Fish/Eggs (MFE) group quantities. Higher GHGE reductions ( $\geq 60 \%$ ) required additional food group modifications, namely an increase of the Starch group quantities and a reduction in quantities of the Fruits and Vegetables (FV) and Dairy Products (Dairy) groups. The Seasonings and Foods High in Fat/Salt/Sugar (HFSS) groups did not deviate from their quantity in the mean observed diet, whatever the strength of the GHGE constraint.

In the ADEQ scenario, respecting the set of nutritional constraints with no imposed reduction of GHGE increased the FV quantity up to approximately $500 \mathrm{~g} / \mathrm{d}$ (Fig. 2(c)). This was explained mainly by an increase in fruit quantity ( $+57 \%$ from the quantity in the observed diet), as shown in Fig. 3(a) presenting the food subgroup quantities. Adding a GHGE constraint up to $40 \%$ reduction did not require any additional changes in food group quantities, except progressively larger decreases in MFE quantities for reductions $\geq 20 \%$. However, other substitutions occurred within food groups (Fig. 3). Within the Dairy food group (Fig. 3(c)), cheese was reduced by almost $50 \%$ from its quantity in the observed diet, in favour of milk. Within the Mixed Dishes food group (Fig. 3(e)), mixed dishes containing animal products were approximately halved 
(a)

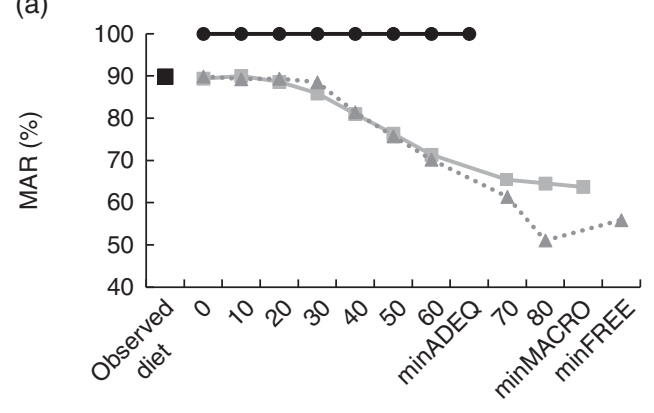

$\%$ GHGE reduction

(c)

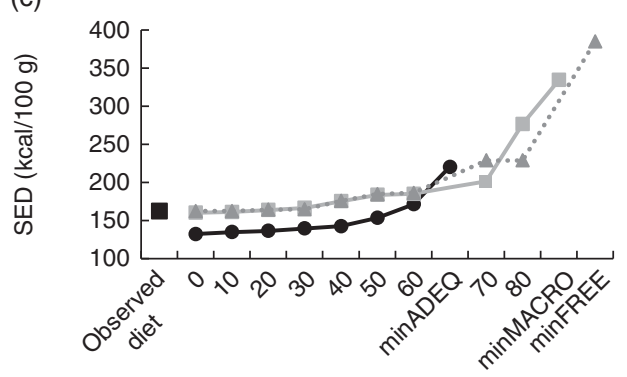

$\%$ GHGE reduction

(e)

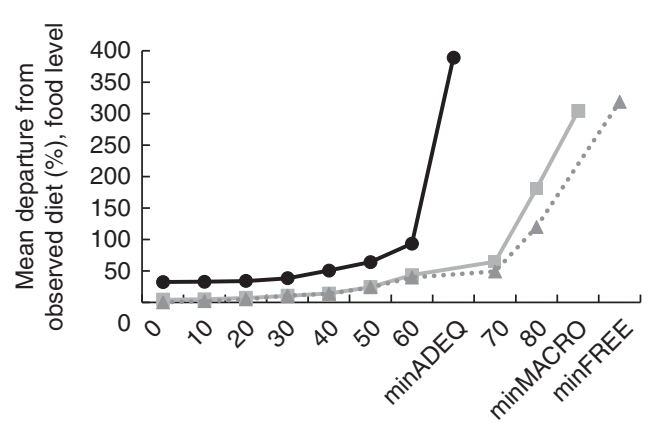

$\%$ GHGE reduction

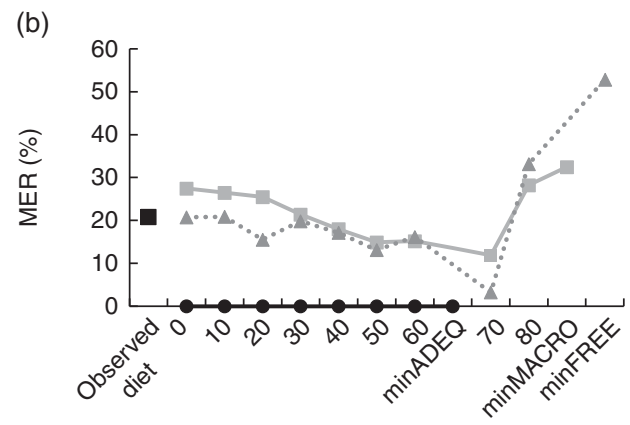

$\%$ GHGE reduction

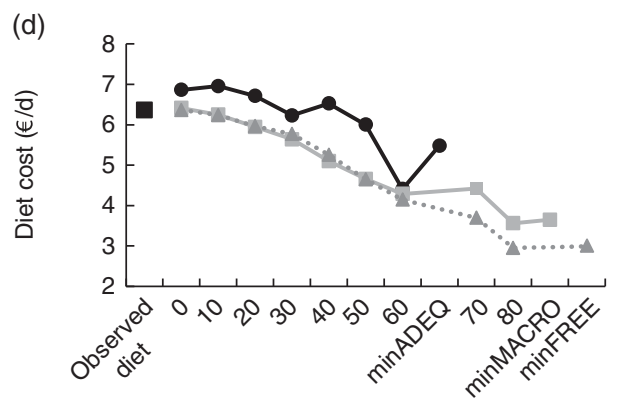

$\%$ GHGE reduction

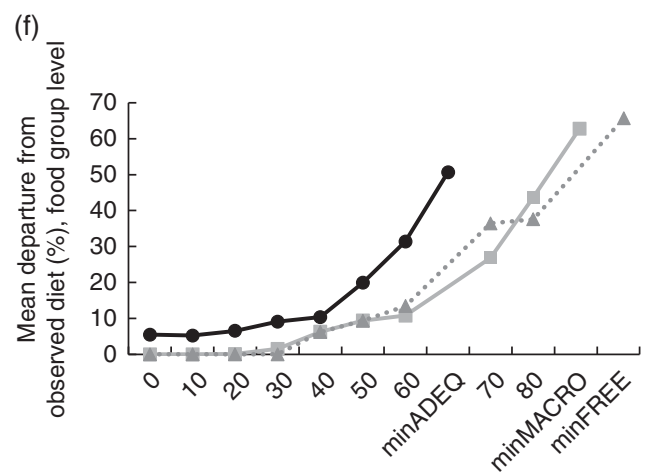

$\%$ GHGE reduction

Fig. 1 (a) Mean adequacy ratio (MAR), (b) mean excess ratio (MER), (c) solid energy density (SED), (d) diet cost, (e) mean departure from the observed diet at food level and (f) mean departure from the observed diet at food group level, for the mean observed diet $(\square)$ and for modelled diets at different levels of dietary GHGE reduction under the FREE (.......), MACRO (-) and ADEQ (-) scenario, for French women (GHGE, greenhouse gas emissions; FREE; no nutritional constraints; MACRO, constraints on macronutrients only; ADEQ, constraints on all nutrients; minFREE, maximal GHGE reduction $(82.6 \%)$ achievable under the constraints of the FREE scenario; minMACRO, maximal GHGE reduction (82.2\%) achievable under the constraints of the MACRO scenario; minADEQ, maximal GHGE reduction $(69.7 \%)$ achievable under the constraints of the ADEQ scenario; $1 \mathrm{kcal}=4.184 \mathrm{~kJ}$ )

in favour of plant-based mixed dishes. Within the MFE food group (Fig. 3(f)), deli and ruminant meats were substituted by the fish subgroup. GHGE reductions higher than $40 \%$ were associated with further decrease in the MFE quantities (suppression of ruminant meat and progressive decrease of the pork, poultry and eggs (PPE) subgroup) together with additional changes at the food group level: the Mixed Dishes group quantity decreased (both animal- and plant-based subgroups) and the Starch group quantity increased (mainly higher quantities of grains and potatoes; Fig. 3(b)). Quantity of the HFSS group remained equal to its levels in the observed diet whatever the GHGE reduction.

\section{Impact of reduction in greenhouse gas emissions on acceptability}

In terms of acceptability, the absolute departure from the mean observed diet remained very low for moderate GHGE reductions in the FREE and MACRO scenarios. In the ADEQ scenario, imposing the set of nutritional constraints with no imposed reduction of GHGE induced a departure of approximately $30 \%$ from the observed 
Table 2 Nutrient levels (percentage of the RDA or percentage of the upper limit) in the mean observed diet and in the FREE, MACRO and ADEQ modelled diets at different levels of GHGE reduction from the value of the mean observed diet for French women

\begin{tabular}{|c|c|c|c|c|c|c|c|c|c|c|c|c|c|c|c|c|c|c|c|c|c|c|c|c|c|c|c|c|c|}
\hline \multirow[b]{3}{*}{ Nutrient } & \multirow{3}{*}{$\begin{array}{c}\text { Observed } \\
\text { diet }\end{array}$} & \multicolumn{10}{|c|}{ FREE } & \multicolumn{10}{|c|}{ MACRO } & \multicolumn{8}{|c|}{ ADEQ } \\
\hline & & \multicolumn{10}{|c|}{$\%$ GHGE reduction } & \multicolumn{10}{|c|}{$\%$ GHGE reduction } & \multicolumn{8}{|c|}{$\%$ GHGE reduction } \\
\hline & & 0 & 10 & 20 & 30 & 40 & 50 & 60 & 70 & 80 & minFREE & 0 & 10 & 20 & 30 & 40 & 50 & 60 & 70 & 80 & minMACRO & 0 & 10 & 20 & 30 & 40 & 50 & 60 & $\min A D E Q$ \\
\hline Proteins & 154 & 154 & 149 & 147 & 141 & 118 & 102 & 94 & 79 & 65 & 74 & 162 & 158 & 152 & 140 & 120 & 103 & 100 & 100 & 100 & 100 & 153 & 150 & 142 & 129 & 123 & 117 & 105 & 126 \\
\hline Carbohydrates & 84 & 84 & 85 & 86 & 89 & 96 & 101 & 103 & 109 & 118 & 109 & 100 & 100 & 100 & 100 & 100 & 103 & 104 & 109 & 109 & 110 & 100 & 100 & 100 & 100 & 100 & 105 & 110 & 101 \\
\hline Fats & 189 & 189 & 190 & 191 & 190 & 184 & 182 & 180 & 174 & 161 & 180 & 146 & 149 & 156 & 163 & 174 & 175 & 175 & 164 & 167 & 163 & 145 & 146 & 151 & 162 & 168 & 159 & 154 & 167 \\
\hline Linoleic acid & 220 & 220 & 225 & 242 & 232 & 224 & 260 & 257 & 326 & 414 & 456 & 155 & 171 & 219 & 222 & 221 & 223 & 374 & 358 & 484 & 454 & 203 & 204 & 208 & 257 & 302 & 269 & 321 & 360 \\
\hline Linolenic acid & 127 & 127 & 128 & 131 & 131 & 127 & 129 & 120 & 108 & 145 & 191 & 116 & 116 & 123 & 124 & 126 & 129 & 116 & 108 & 140 & 190 & 122 & 117 & 124 & 135 & 123 & 135 & 146 & 152 \\
\hline $\mathrm{EPA}+\mathrm{DHA}$ & 140 & 140 & 147 & 180 & 386 & 133 & 104 & 99 & 29 & 11 & 6 & 139 & 146 & 149 & 145 & 133 & 104 & 109 & 131 & 74 & 38 & 239 & 244 & 231 & 229 & 270 & 284 & 242 & 336 \\
\hline PUFA & 106 & 106 & 108 & 116 & 116 & 107 & 121 & 119 & 145 & 185 & 206 & 78 & 85 & 105 & 106 & 106 & 106 & 168 & 161 & 215 & 206 & 100 & 100 & 102 & 123 & 142 & 129 & 151 & 170 \\
\hline $\mathrm{Ca}$ & 93 & 93 & 95 & 96 & 96 & 91 & 77 & 72 & 51 & 47 & 41 & 96 & 98 & 95 & 90 & 90 & 79 & 76 & 55 & 46 & 41 & 100 & 100 & 100 & 100 & 100 & 100 & 100 & 100 \\
\hline $\mathrm{Cu}$ & 98 & 98 & 98 & 97 & 89 & 87 & 86 & 83 & 73 & 70 & 79 & 98 & 98 & 97 & 89 & 86 & 88 & 82 & 75 & 81 & 76 & 150 & 150 & 150 & 145 & 145 & 148 & 149 & 101 \\
\hline $\mathrm{Fe}$ & 68 & 68 & 68 & 66 & 66 & 61 & 57 & 60 & 67 & 73 & 86 & 73 & 73 & 70 & 68 & 60 & 60 & 60 & 72 & 87 & 89 & 100 & 100 & 100 & 102 & 100 & 110 & 136 & 153 \\
\hline Fibre & 56 & 56 & 57 & 58 & 61 & 61 & 61 & 59 & 59 & 54 & 57 & 59 & 60 & 61 & 63 & 62 & 62 & 58 & 56 & 54 & 61 & 100 & 100 & 100 & 100 & 100 & 100 & 100 & 100 \\
\hline lodine & 80 & 80 & 85 & 87 & 90 & 75 & 66 & 68 & 63 & 58 & 30 & 82 & 84 & 88 & 85 & 74 & 68 & 72 & 75 & 61 & 36 & 100 & 100 & 100 & 100 & 100 & 100 & 100 & 100 \\
\hline Mg & 81 & 81 & 74 & 71 & 68 & 62 & 57 & 55 & 50 & 49 & 91 & 81 & 80 & 70 & 66 & 62 & 58 & 57 & 56 & 84 & 95 & 108 & 106 & 102 & 106 & 103 & 103 & 120 & 150 \\
\hline $\mathrm{P}$ & 150 & 150 & 149 & 148 & 144 & 126 & 111 & 98 & 74 & 62 & 110 & 154 & 154 & 149 & 140 & 126 & 112 & 104 & 90 & 103 & 125 & 176 & 175 & 175 & 166 & 163 & 157 & 147 & 199 \\
\hline K & 88 & 88 & 79 & 78 & 75 & 68 & 64 & 55 & 45 & 37 & 36 & 88 & 87 & 77 & 73 & 67 & 64 & 57 & 46 & 39 & 41 & 106 & 100 & 100 & 100 & 100 & 100 & 100 & 100 \\
\hline $\mathrm{Se}$ & 194 & 194 & 196 & 219 & 234 & 216 & 211 & 205 & 187 & 177 & 186 & 189 & 192 & 212 & 214 & 210 & 211 & 212 & 242 & 330 & 216 & 193 & 189 & 217 & 219 & 248 & 240 & 208 & 230 \\
\hline Vitamin A & 178 & 178 & 182 & 171 & 154 & 143 & 118 & 84 & 64 & 32 & 9 & 165 & 172 & 170 & 151 & 134 & 118 & 76 & 57 & 26 & 9 & 170 & 161 & 171 & 162 & 195 & 173 & 136 & 147 \\
\hline Thiamin & 100 & 100 & 100 & 98 & 95 & 83 & 72 & 68 & 56 & 47 & 95 & 101 & 101 & 98 & 95 & 82 & 72 & 69 & 64 & 68 & 100 & 114 & 115 & 114 & 111 & 103 & 100 & 100 & 143 \\
\hline Riboflavin & 108 & 108 & 108 & 105 & 98 & 83 & 73 & 64 & 40 & 29 & 40 & 110 & 113 & 107 & 96 & 84 & 73 & 67 & 46 & 37 & 42 & 126 & 121 & 120 & 115 & 107 & 100 & 100 & 100 \\
\hline Niacin & 152 & 152 & 140 & 128 & 120 & 95 & 82 & 74 & 60 & 60 & 70 & 154 & 146 & 131 & 117 & 95 & 82 & 77 & 67 & 104 & 80 & 182 & 185 & 175 & 159 & 147 & 150 & 151 & 150 \\
\hline Vitamin $B_{12}$ & 376 & 376 & 362 & 362 & 408 & 294 & 268 & 239 & 186 & 27 & 18 & 378 & 365 & 352 & 315 & 294 & 268 & 266 & 192 & 145 & 123 & 246 & 236 & 225 & 203 & 326 & 293 & 176 & 228 \\
\hline $\begin{array}{l}\text { Pantothenic } \\
\text { acid }\end{array}$ & 98 & 98 & 99 & 97 & 91 & 73 & 65 & 58 & 48 & 38 & 39 & 99 & 104 & 97 & 89 & 73 & 65 & 59 & 50 & 43 & 45 & 122 & 118 & 118 & 113 & 104 & 100 & 100 & 100 \\
\hline Vitamin $B_{6}$ & 104 & 104 & 101 & 97 & 96 & 79 & 70 & 63 & 56 & 47 & 78 & 102 & 99 & 94 & 89 & 78 & 71 & 64 & 54 & 60 & 78 & 136 & 137 & 135 & 130 & 122 & 124 & 125 & 150 \\
\hline Folic acid & 87 & 87 & 86 & 87 & 82 & 75 & 66 & 58 & 53 & 36 & 29 & 91 & 93 & 90 & 82 & 74 & 67 & 58 & 51 & 42 & 33 & 108 & 103 & 109 & 104 & 100 & 100 & 100 & 102 \\
\hline Vitamin C & 89 & 89 & 88 & 88 & 82 & 80 & 78 & 50 & 43 & 27 & 12 & 86 & 86 & 86 & 77 & 79 & 78 & 50 & 33 & 15 & 11 & 100 & 100 & 100 & 100 & 100 & 100 & 102 & 100 \\
\hline Vitamin D & 70 & 70 & 76 & 86 & 161 & 61 & 47 & 42 & 15 & 13 & 9 & 68 & 74 & 74 & 72 & 60 & 47 & 45 & 35 & 16 & 7 & 100 & 100 & 100 & 100 & 100 & 100 & 100 & 100 \\
\hline Vitamin E & 104 & 104 & 107 & 122 & 127 & 132 & 157 & 163 & 215 & 250 & 232 & 75 & 86 & 93 & 105 & 123 & 135 & 198 & 197 & 235 & 223 & 111 & 109 & 119 & 129 & 183 & 131 & 143 & 191 \\
\hline $\mathrm{Zn}$ & 88 & 88 & 79 & 78 & 73 & 65 & 58 & 54 & 52 & 52 & 64 & 91 & 83 & 80 & 73 & 65 & 59 & 57 & 64 & 74 & 75 & 103 & 100 & 100 & 100 & 100 & 100 & 106 & 123 \\
\hline Choles & 100 & 100 & 117 & 117 & 110 & 67 & 41 & 36 & 26 & 6 & 3 & 92 & 110 & 116 & 108 & 68 & 41 & 37 & 34 & 12 & 7 & 100 & 100 & 100 & 93 & 67 & 48 & 18 & 16 \\
\hline Free sugars* & 99 & 99 & 99 & 99 & 98 & 118 & 120 & 124 & 109 & 195 & 258 & 131 & 126 & 126 & 119 & 120 & 122 & 122 & 106 & 177 & 197 & 100 & 100 & 100 & 99 & 100 & 95 & 97 & 100 \\
\hline $\mathrm{Na}^{*}$ & 119 & 119 & 120 & 124 & 139 & 122 & 119 & 120 & 101 & 105 & 53 & 138 & 141 & 139 & 136 & 126 & 121 & 121 & 130 & 108 & 81 & 100 & 100 & 100 & 100 & 100 & 100 & 100 & 81 \\
\hline $\mathrm{SFA}^{*}$ & 143 & 143 & 142 & 123 & 120 & 111 & 100 & 105 & 94 & 77 & 82 & 113 & 113 & 111 & 109 & 108 & 101 & 102 & 91 & 76 & 60 & 100 & 100 & 100 & 100 & 100 & 100 & 99 & 87 \\
\hline
\end{tabular}

FREE; no nutritional constraints; MACRO, constraints on macronutrients only; ADEQ, constraints on all nutrients; GHGE, greenhouse gas emissions; minFREE, maximal GHGE reduction (82.6\%) achievable under the

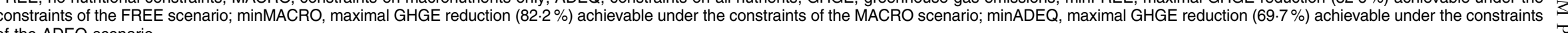
of the ADEQ scenario.

RDA unless otherwise stated.

*Percentage of the upper limit. 
(a)

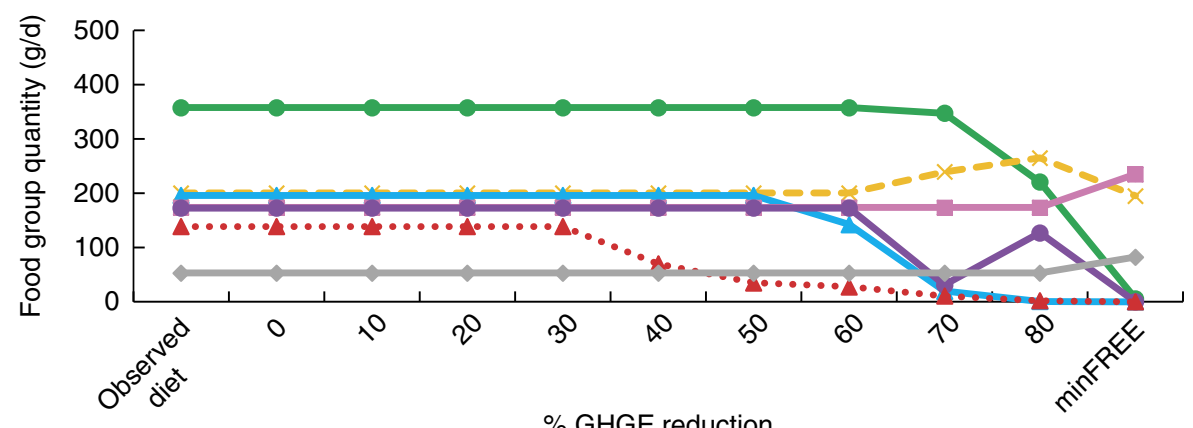

$\%$ GHGE reduction

(b)

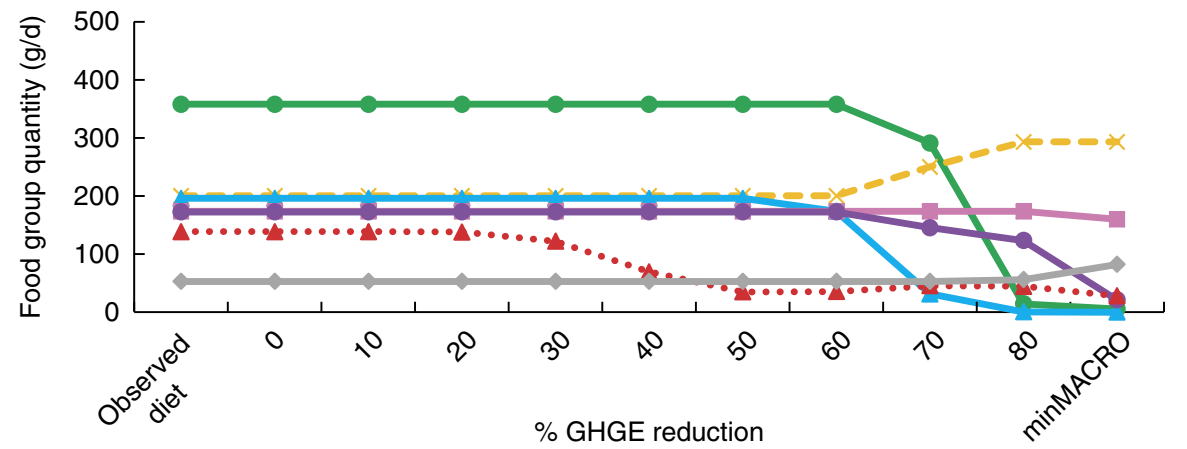

(c)

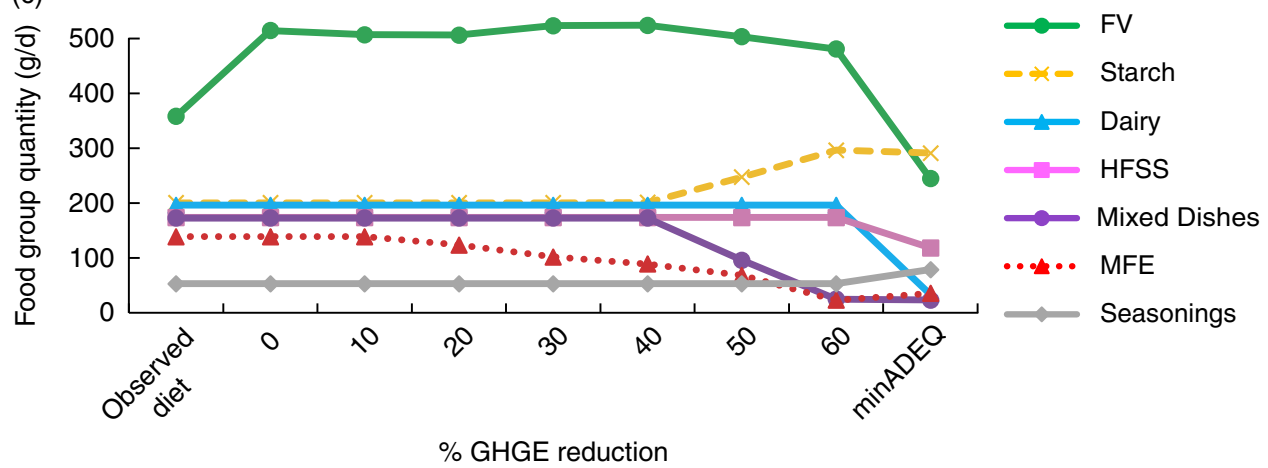

Fig. 2 Food group quantities $(\mathrm{g} / \mathrm{d})$ in the mean observed diet and at different levels of dietary GHGE reduction from the value of the mean observed diet under the FREE (a), MACRO (b) and ADEQ (c) modelled diets for French women (GHGE, greenhouse gas emissions; FREE; no nutritional constraints; MACRO, constraints on macronutrients only; ADEQ, constraints on all nutrients; FV, Fruits and Vegetables; Dairy, Dairy Products; HFSS, Foods High in Fat/Sugar/Salt; MFE, Meat/Fish/Eggs; minFREE, maximal GHGE reduction (82.6\%) achievable under the constraints of the FREE scenario; minMACRO, maximal GHGE reduction (82.2\%) achievable under the constraints of the MACRO scenario; minADEQ, maximal GHGE reduction (69.7\%) achievable under the constraints of the ADEQ scenario)

diet at the food level and of $5 \%$ at the food group level (Fig. 1(e) and 1(f)). For moderate GHGE reductions $(\leq 30 \%)$, the absolute departure remained close to these values. Higher GHGE reductions (>30\%) increased departure from the observed diet significantly.

\section{Impact of reduction in greenbouse gas emissions on diet cost}

The cost of the mean observed diet was $6 \cdot 4 €$ /d (Fig. 1(d)). The cost of the diets modelled under the FREE and MACRO scenarios were similar to or lower than the cost of the mean observed diet. Under those scenarios, strengthening the GHGE constraint tended to reduce diet cost.

Imposing the nutritional constraints of the ADEQ scenario slightly increased the cost of the diet. High GHGE reductions $(\geq 50 \%)$ decreased diet cost.

\section{Minimization of greenbouse gas emissions}

Changing the objective function for a minimization of GHGE induced dramatic changes in terms of diet composition (Figs 2 and 3). Minimizing the GHGE induced elimination of the Dairy group for both FREE and MACRO 

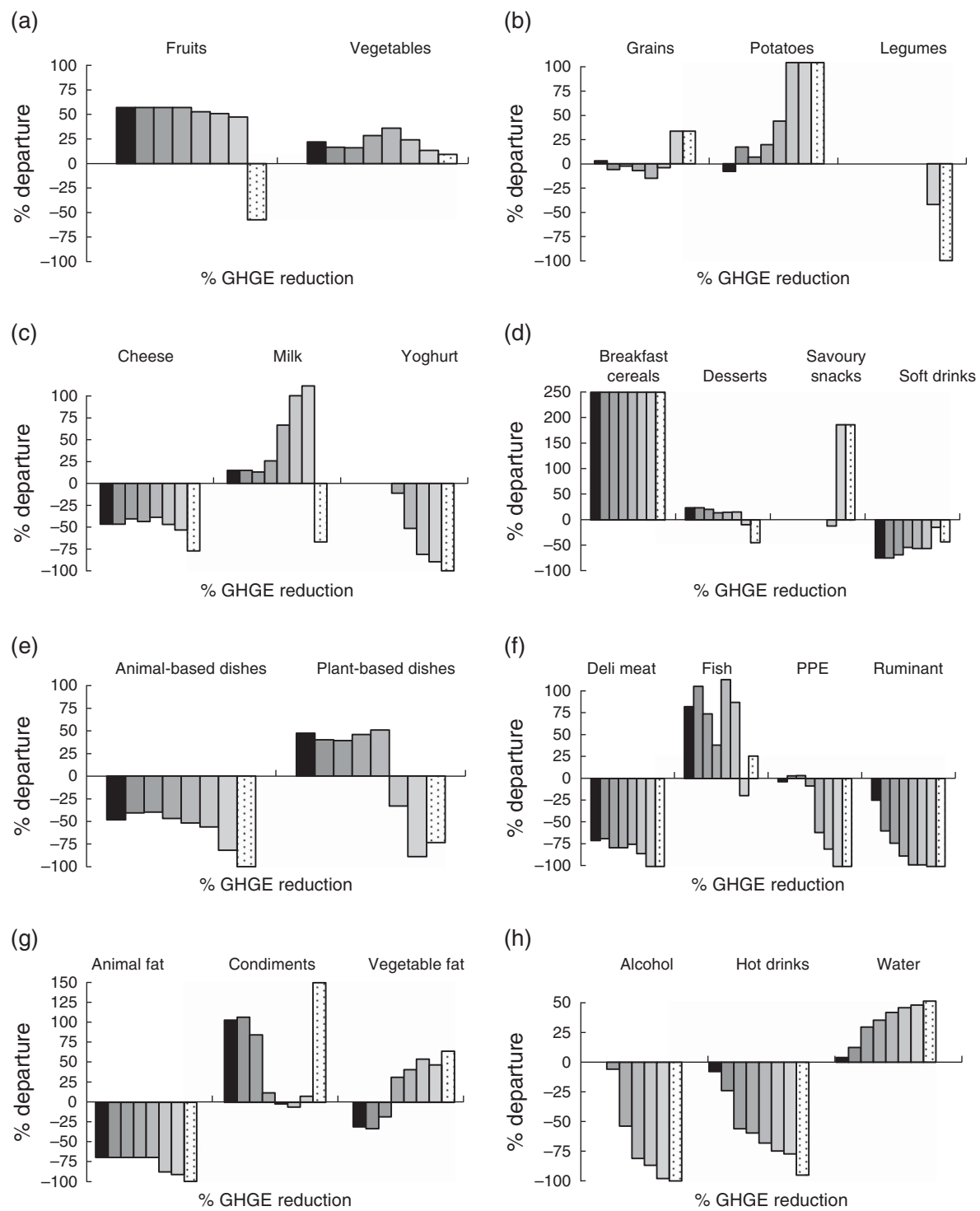

Fig. 3 Departure from subgroup quantities in the observed diet (\%) for the ADEQ scenario at different levels of dietary GHGE reduction (\% GHGE reduction: $\square, 0 ; \square, 10 ; \square, 20 ; \square, 30 ; \square, 40 ; \square, 50 ; \square, 60 ; \square$, min) for French women, according to food group: (a) Fruits and Vegetables; (b) Starch; (c) Dairy Products; (d) Foods High in Fat/Sugar/Salt; (e) Mixed Dishes; (f) Meat/Fish/Eggs; (g) Seasonings; (h) Drinks (ADEQ, constraints on all nutrients; GHGE, greenhouse gas emissions; min: maximal GHGE reduction $(69.7 \%)$ achievable under the constraints of the ADEQ scenario; PPE, pork, poultry and eggs)

scenarios (Fig. 2(a) and 2(b)). Without any nutritional constraints (FREE scenario), the MFE and Mixed Dishes groups were also eliminated, while FV was reduced to less than $6 \mathrm{~g} / \mathrm{d}$, leading to a modelled diet composed mainly of three food groups: HFSS, Starch and Seasonings, with almost half of the energy provided by HFSS. In the ADEQ scenario, minimizing the GHGE did not suppress any food category, but induced reductions of the FV quantity down to $245 \mathrm{~g} / \mathrm{d}$ and of MFE down to $35 \mathrm{~g} / \mathrm{d}$.

\section{Strength of nutritional constraints}

The comparative strength of each nutritional constraint was evaluated through the analysis of dual values (data not shown). In the MACRO scenario, the most difficult constraint to meet was the minimum energy contribution of carbohydrates ( $\geq 50 \%$ ) for GHGE reductions $\leq 50 \%$ and of proteins $(\geq 10 \%)$ for highest GHGE reductions. In the ADEQ scenario, the minimum quantity of fibre ( $>30 \mathrm{~g}$ ) was the most difficult constraint to meet. Respecting the upper limit of $\mathrm{Na}(<2365 \mathrm{mg})$ was also constraining, especially for GHGE reductions $<40 \%$. Strengthening of the GHGE constraint increased the difficulty in meeting the recommendations for $\mathrm{Ca}$ and $\mathrm{K}$. These two recommendations were the most difficult to meet, followed by fibre, when GHGE was minimized.

The main impacts of GHGE reductions on the nutritional quality, diet composition and diet cost observed 
for women were similar for men's models. These are presented in the online supplementary material, Supplemental Table 2 and Supplemental Figs 1-3.

\section{Discussion}

Based on three nationally representative French data sets, namely on dietary intakes, food prices and food GHGE, the present study shows that diet-related GHGE may be reduced by $30 \%$ while reaching nutritional adequacy without requiring major additional dietary shifts, at the food group level, than those induced by meeting nutritional recommendations, and at a similar cost. Combining cultural acceptability and nutritional adequacy at higher GHGE reductions (>30\%) was not achievable. Such GHGE reductions either impaired nutritional quality, even when recommendations on macronutrients were imposed, or required non-trivial dietary shifts compromising acceptability to reach nutritional adequacy.

By modelling diets at increasingly stringent levels of nutritional constraints, the present study shows that the nutritional dimension of diet sustainability should not be overlooked when acting on GHGE mitigation. Imposing constraints on macronutrients only (proteins, lipids and carbohydrates) did not ensure nutritional adequacy any better than with no nutritional constraint, and even impaired it: the MER actually increased for moderate GHGE reductions ( $\leq 30 \%$ ), indicating higher quantities of nutrients to be limited, namely free sugars and $\mathrm{Na}$. Imposing higher GHGE reductions (>30\%) without stringent nutritional constraints decreased the MAR, indicating a diet with lower quantities of beneficial nutrients. Hence in the absence of constraints imposing nutritional adequacy, nutritional quality was impaired by GHGE reduction. These results highlight the need to consider the nutritional dimension through appropriate indicators when investigating alternative diets with lower environmental impact.

By modelling diets minimizing the GHGE, the present study showed that the maximal GHGE reduction achievable from the observed level, while respecting all the nutritional recommendations, was $69.7 \%$ for women and $74.0 \%$ for men. A similar level of GHGE reduction (70\%) was investigated by Audsley et al. through a combination of mitigation measures from different sectors ${ }^{(6)}$. Sáez-Almendros et al. also suggested that a shift towards a Mediterranean diet would result in a $72 \%$ reduction of the Spanish $\mathrm{GHGE}^{(41)}$, but this required extreme energy restrictions. Our results showed that reaching the maximal reductions of $69.7 \%$ and $74.0 \%$ without energy restrictions required extreme food pattern changes and departure from the observed diet, thus compromising the acceptability of such alternative diets. The model could not identify a combination of foods respecting all the constraints for higher GHGE reductions (>70\%), indicating that nutritional adequacy could not be reached with habitual food items for such a level of GHGE reduction. The nutrients for which needs were the most difficult to fulfil for high GHGE reductions were fibre, $\mathrm{Ca}$ and $\mathrm{K}$.

By modelling diets at increasingly stringent levels of nutritional and GHGE constraints, the present study reveals that moderate GHGE reductions did not require any dietary shifts at the food group level additional to those induced by meeting nutritional recommendations, i.e. mainly an increase in fruits and vegetables. This indicates that adopting a nutritionally adequate diet could be coupled to moderate GHGE reductions, and thus would benefit both the environmental and the nutritional dimensions of diet sustainability. However, reaching nutritional adequacy at higher GHGE reductions required further dietary shifts, namely a reduction of foods of animal origin (except fish products), and especially deli and ruminant meats, from $20 \%$ GHGE reduction. The progressive reduction of meat products when the GHGE constraint was strengthened confirmed the role of animalbased foods as the main levers to reduce diet-related $\mathrm{GHGE}^{(5,42,43)}$. GHGE reductions higher than $40 \%$ required an increase in quantity of the starchy food group, which was the main component (approximately one-third of the total energy) of the nutritionally adequate diet minimized on GHGE. Moreover, without adequate constraints on micronutrients, high GHGE reductions resulted in the elimination of some food groups, namely Dairy and MFE. Conversely, all food groups were represented in nutritionally adequate diets with reduced GHGE (ADEQ), even when GHGE were minimized. Hence while vegetarian or vegan diets are often claimed to reduce the environmental impact of diet, the results of the present study suggest that food group diversity must be preserved to improve diet sustainability, rather than drastic dietary changes excluding food categories. Previous studies have estimated that shifting from the average diet to a vegetarian diet would reduce GHGE by $22 \%$ in the $\mathrm{UK}^{(44)}$ or $27 \%$ in Den$\operatorname{mark}^{(45)}$. However, the realism of such scenarios is questionable since the prevalence of vegetarianism is quite low in industrialized countries (e.g. estimated to be approximately $2 \%$ in the French ${ }^{(46)}$ and $\mathrm{US}^{(47)}$ populations). In addition, some studies suggest that a large proportion of the population is not yet ready to consume a fully plantbased diet $^{(48,49)}$. According to the present results, 30\% GHGE reduction could be achieved in a nutritionally adequate diet by increasing fruits and vegetables while maintaining intake of meat/fish/eggs at approximately $100 \mathrm{~g} / \mathrm{d}$, mainly by substituting ruminant and deli meats by fish products.

The main strength of the present study was taking into account simultaneously several dimensions of diet sustainability, namely nutritional adequacy, environmental impact, affordability and cultural acceptability. The latter was considered by minimizing the departure from the 
observed diet and through constraints applied on food quantities based on the most recent dietary survey conducted in the French population. Also, whereas previous diet modelling studies were based on eighty-two foods in the $\mathrm{UK}^{(22)}$ and seventy-six foods items in New Zealand ${ }^{(23)}$, the diets modelled in the present study were based on consumption, nutritional composition, GHGE and price of 402 foods identified among those most consumed by the INCA2 participants and representing the consumption of the 1342 foods declared in the national survey.

A further strength of the study was the reliability of the environmental data. Whereas most of the studies assessing the environmental impact of diet are based on environmental data compiled from heterogeneous studies conducted under different LCA modelling hypotheses or specific in terms of geographical situation or production modes, the present study was based on GHGE data built from a hybrid input-output/LCA standardized method applied to the 402 food items, thus ensuring reliably sourced data representative of national food consumption and production modes ${ }^{(32)}$.

However, a limitation of the present study was that nutritional adequacy may have been compromised by varying bioavailability of some key nutrients for which animal sources are known to be more favourable ${ }^{(50-52)}$. In this context, Fe has been highlighted as of particular concern since animal products are the only source of haem $\mathrm{Fe}$, the most bioavailable source of Fe. Hence further improvements of the models could be achieved by taking the bioavailability of such nutrients into account. Also, other indicators of the environmental impact of diet should be considered. Food production has been shown to account for most of the global water footprint ${ }^{(53)}$ and agricultural production, being an integral part of many ecosystems, can restrict or promote their biodiversity, resilience and socio-economic functions. In particular, biodiversity is of great concern in fish production. Future modelling studies could thus benefit from including additional environmental indicators, but the main obstacles to such improvements are the limited availability and access to data at the food level. This study could also be further improved by using an individual diet modelling approach to integrate individual food preferences. Moreover, in our study, acceptability was taken into account by minimizing the departure from the observed diet in terms of food and food group contents, in order to limit the deterioration of cultural acceptability induced by the modelling. However, such method cannot guarantee that the proposed shift modelled by the linear programming would be acceptable to the consumer. In particular, it is a strong, and perhaps unjustified, assumption that departing the least from the mean diet, in terms of food groups defined on a nutritional basis rather than on practical and/or monetary ones, will be more acceptable to the consumer. Some recent modelling studies considered the acceptability dimension by introducing price elasticity and food expenditure shares in the model to better control the level and type of deviation from current $\operatorname{diet}^{(54)}$. However, incorporating information on consumer behaviour still does not necessarily ensure that dietary scenarios would be fully acceptable ${ }^{(55)}$. This emphasizes the importance of coupling the identification of more sustainable diets with studies on interventions and tools aimed at favouring their adoption by consumers in real life.

\section{Conclusion}

The current modelling study highlights the need to consider the nutritional dimension through relevant indicators when assessing how to improve diet sustainability. It also shows that nutritional adequacy, cultural acceptability and affordability of the diet may not be compatible with GHGE reductions higher than $30 \%$. This underlines the limits of the food consumption shift strategy to reduce GHGE and emphasizes that reaching GHGE reduction targets requires to combine mitigation approaches from different sectors, including production efficiency, demand restraint and food system transformation ${ }^{(56)}$.

\section{Acknowledgements}

Financial support: M.P. was supported by the Daniel \& Nina Carasso Foundation under the Avasun project; G.M. was supported by the French National Research Agency under the OCAD project (ANR-11-ALID-0002) and by the Daniel \& Nina Carasso Foundation under the Avasun project; GF was supported by the French National Research Agency under the Medina project (ANR-12TMED-0004); T.B. was financially supported by the SPSA (Science des Procédés et des Aliments) graduate school. The funders had no role in the design, analysis or writing of this article. Conflict of interest: None. Authorship: M.P. and G.M. contributed equally to this work. N.D., M.P., G.M., M.-J.A. and G.F. designed and conducted the research and wrote the manuscript; G.F., T.B., M.P., F.V. and M.M. analysed the data; and N.D. had primary responsibility for the final content. All authors read and approved the final manuscript. Ethics of human subject participation: Not applicable.

\section{Supplementary material}

To view supplementary material for this article, please visit http://dx.doi.org/10.1017/S1368980016000653

\section{References}

1. Food and Agriculture Organization of the United Nations (2010) Sustainable diets and biodiversity - directions and solutions for policy, research and action. In International 
Scientific Symposium 'Biodiversity and Sustainable Diets United Against Hunger'. http://www.fao.org/ag/human nutrition/28507-0e8d8dc364ee46865d5841c48976e9980.pdf (accessed July 2015).

2. European Commission (2011) Communication from the Commission to the European Parliament, the Council, the European Economic and Social Committee and the Committee of the Regions: A Roadmap for Moving to a Competitive Low Carbon Economy in 2050. Brussels: European Commission.

3. Parliament of the United Kingdom (2008) Climate Change Act 2008 (c. 27). http://www.legislation.gov.uk/ukpga/ 2008/27/contents (accessed March 2016).

4. République Française (2009) LOI n²009-967 du 3 août 2009 de programmation relative à la mise en œuvre du Grenelle de l'environnement. https://www.legifrance.gouv. fr/affichTexte.do?cidTexte=JORFTEXT000020949548\&cate gorieLien=id (accessed March 2016).

5. Stehfest E, Bouwman L, van Vuuren D et al. (2009) Climate benefits of changing diet. Climatic Change 95, 83-102.

6. Audsley E, Brander M, Chatterton J et al. (2009) How Low Can We Go? An Assessment of Greenhouse Gas Emissions from the UK Food System and the Scope for Reduction by 2050. UK: WWF-UK

7. World Health Organization \& Food and Agriculture Organization of the United Nations (2003) Diet, Nutrition, and the Prevention of Chronic Diseases. Report of a Joint WHO/ FAO Expert Consultation. WHO Technical Report Series no. 916. Geneva: WHO.

8. Friel S, Dangour AD, Garnett T et al. (2009) Public health benefits of strategies to reduce greenhouse-gas emissions: food and agriculture. Lancet 374, 2016-2025.

9. Tukker A, Goldbohm RA, de Koning A et al. (2011) Environmental impacts of changes to healthier diets in Europe. Ecol Econ 70, 1776-1788.

10. Scarborough P, Allender S, Clarke D et al. (2012) Modelling the health impact of environmentally sustainable dietary scenarios in the UK. Eur J Clin Nutr 66, 710-715.

11. Aston LM, Smith JN \& Powles JW (2012) Impact of a reduced red and processed meat dietary pattern on disease risks and greenhouse gas emissions in the UK: a modelling study. BMJ Open 2, e001072.

12. Monsivais P, Scarborough P, Lloyd T et al. (2015) Greater accordance with the dietary approaches to stop hypertension dietary pattern is associated with lower diet-related greenhouse gas production but higher dietary costs in the United Kingdom. Am J Clin Nutr 102, 138-145.

13. Biesbroek S, Bueno-de-Mesquita HB, Peeters PHM et al. (2014) Reducing our environmental footprint and improving our health: greenhouse gas emission and land use of usual diet and mortality in EPIC-NL: a prospective cohort study. Environ Health 13, 27.

14. Vieux F, Soler L-G, Touazi D et al. (2013) High nutritional quality is not associated with low greenhouse gas emissions in self-selected diets of French adults. Am J Clin Nutr 97, 569-583.

15. Masset G, Vieux F, Verger EO et al. (2014) Reducing energy intake and energy density for a sustainable diet: a study based on self-selected diets in French adults. Am J Clin Nutr 99, $1460-1469$.

16. Andrieu E, Darmon N \& Drewnowski A (2006) Low-cost diets: more energy, fewer nutrients. Eur J Clin Nutr 60, 434-436.

17. Darmon N \& Drewnowski A (2015) Contribution of food prices and diet cost to socioeconomic disparities in diet quality and health: a systematic review and analysis. Nutr Rev 73, 643-660.

18. Maillot M, Vieux F, Amiot MJ et al. (2010) Individual diet modeling translates nutrient recommendations into realistic and individual-specific food choices. Am J Clin Nutr $\mathbf{9 1}$, 421-430.
19. Darmon N, Ferguson EL \& Briend A (2006) Impact of a cost constraint on nutritionally adequate food choices for French women: an analysis by linear programming. J Nutr Educ Behav 38, 82-90.

20. Buttriss JL, Briend A, Darmon N et al. (2014) Diet modelling: how it can inform the development of dietary recommendations and public health policy. Nutr Bull 39, 115-125.

21. Masset G, Monsivais P, Maillot M et al. (2009) Diet optimization methods can help translate dietary guidelines into a cancer prevention food plan. J Nutr 139, 1541-1548.

22. Macdiarmid JI, Kyle J, Horgan GW et al. (2012) Sustainable diets for the future: can we contribute to reducing greenhouse gas emissions by eating a healthy diet? Am J Clin Nutr 96, 632-639.

23. Wilson N, Nghiem N, Ni Mhurchu C et al. (2013) Foods and dietary patterns that are healthy, low-cost, and environmentally sustainable: a case study of optimization modeling for New Zealand. PLoS One 8, e59648.

24. Lafay L, Bénetier C, Bertin M et al. (2009) Étude Individuelle Nationale des Consommations Alimentaires 2 (INCA 2) 2006-2007. Maisons-Alfort: Afssa.

25. Black AE (2000) Critical evaluation of energy intake using the Goldberg cut-off for energy intake:basal metabolic rate. A practical guide to its calculation, use and limitations. Int J Obes Relat Metab Disord 24, 1119-1130.

26. International Organization for Standardization (2006) ISO 14040:2006 Environmental Management - Life Cycle Assessment - Principles and Framework. Geneva: ISO.

27. International Organization for Standardization (2006) ISO 14044:2006 Environmental Management - Life Cycle Assessment - Requirements and Guidelines. Geneva: ISO.

28. Association Française de Normalisation (2011) BP X30-323principes généraux pour l'affichage environnenemental des produits de grande consummation (General principles for environmental labelling of consumer products). La Plaine Saint-Denis: AFNOR (in French).

29. National Institute of Statistics and Economic Studies (2013) Definitions, methods and quality. Statistical operation: Survey on industrial energy consumption (EACEI). http:// www.insee.fr/en/methodes/default.asp?page=sources/ope-enqconso-energie-industrie-eacei.htm (accessed March 2016).

30. French Department of Ecology, Sustainable Development and Energy (2013) SitraM database. http://www.statistiques. developpement-durable.gouv.fr/donnees-ligne/r/flux-march andises-sitram-i.html?tx_ttnews\%5btt_news $\% 5 \mathrm{~d}=20519 \%$ 26cHash=a891e4085d89a9486f97d0282957ec1a (accessed March 2013).

31. Althaus H, Doka G, Dones R et al. (2007) Overview and Methodology-Data v2.0-Ecoinvent Report No. 1. Dübendorf: Ecoinvent.

32. Bertoluci G, Masset G, Gomy C et al. (2016) How to build a standardized country-specific environmental food database for nutritional epidemiological studies. PLoS One (In the Press).

33. World Health Organization/Food and Agriculture Organization of the United Nations/United Nations University (2002) Joint FAO/WHO/UNU Expert Consultation on Protein and Amino Acid Requirements in Human Nutrition. Geneva: WHO.

34. Mann J, Cummings JH, Englyst HN et al. (2007) FAO/WHO scientific update on carbohydrates in human nutrition: conclusions. Eur J Clin Nutr 61, Suppl. 1, S132-S137.

35. Food and Agriculture Organization of the United Nations \& World Health Organization (2008) Interim Summary of Conclusions and Dietary Recommendations on Total Fat \& Fatty Acids. From the Joint FAO/WHO Expert Consultation on Fats and Fatty Acids in Human Nutrition, November 1014, 2008, WHO HQ, Geneva. http://www.fao.org/ag/agn/ nutrition/docs/Fats\%20and\%20Fatty\%20Acids\%20Summary. pdf (accessed March 2016). 
36. Martin A (2001) Apports nutritionnels conseillés pour la population française, 3ème édition [Afssa, editor]. Paris: Lavoisier.

37. Pietinen P, Valsta LM, Hirvonen T et al. (2008) Labelling the salt content in foods: a useful tool in reducing sodium intake in Finland. Public Health Nutr 11, 335-340.

38. Hercberg S, Chat-Yung S \& Chauliac M (2008) The French National Nutrition and Health Program: 2001-2006-2010. Int J Public Health 53, 68-77.

39. Ledikwe JH, Blanck HM, Khan LK et al. (2005) Dietary energy density determined by eight calculation methods in a nationally representative United States population. $J$ Nutr 135, 273-278.

40. Kantar Worldpanel (2013) French household consumer panel - Kantar Worldpanel. http://www.kantarworldpanel. com/global/Sectors (accessed May 2013).

41. Sáez-Almendros S, Obrador B, Bach-Faig A et al. (2013) Environmental footprints of Mediterranean versus Western dietary patterns: beyond the health benefits of the Mediterranean diet. Environ Health 12, 118.

42. McMichael AJ, Powles JW, Butler CD et al. (2007) Food, livestock production, energy, climate change, and health. Lancet 370, 1253-1263.

43. Committee on Climate Change (2010) Reducing emissions from agriculture and land use, land-use change and forestry. In The Fourth Carbon Budget - Reducing Emissions through 2020s, pp. 295-329. London: CCC.

44. Berners-Lee M, Hoolohan C, Cammack H et al. (2012) The relative greenhouse gas impacts of realistic dietary choices. Energy Policy 43, 184-190.

45. Saxe H, Larsen TM \& Mogensen L (2012) The global warming potential of two healthy Nordic diets compared with the average Danish diet. Climatic Change 116, 249-262.

46. Leblanc JC, Yoon H, Kombadjian A et al. (2000) Nutritional intakes of vegetarian populations in France. Eur J Clin Nutr 54, 443-449.
47. Craig WJ \& Mangels AR, Ada (2009) Position of the American Dietetic Association: vegetarian diets. J Am Diet Assoc 109, 1266-1282.

48. Lea EJ, Crawford D \& Worsley A (2006) Consumers' readiness to eat a plant-based diet. Eur J Clin Nutr 60, 342-351.

49. Vanhonacker F, Van Loo EJ, Gellynck X et al. (2013) Flemish consumer attitudes towards more sustainable food choices. Appetite 62, 7-16.

50. American Dietetic Association \& Dietitians of Canada (2003) Position of the American Dietetic Association and Dietitians of Canada: vegetarian diets. J Am Diet Assoc 103, 748-765.

51. Gibson RS, Bailey KB, Gibbs M et al. (2010) A review of phytate, iron, zinc, and calcium concentrations in plantbased complementary foods used in low-income countries and implications for bioavailability. Food Nutr Bull 31, 2 Suppl., S134-S146.

52. Haddad EH, Berk LS, Kettering JD et al. (1999) Dietary intake and biochemical, hematologic, and immune status of vegans compared with nonvegetarians. Am J Clin Nutr 70, 3 Suppl., 586S-593S.

53. Vanham D, Mekonnen MM \& Hoekstra AY (2013) The water footprint of the EU for different diets. Ecol Indic 32, 1-8.

54. Milner J, Green R, Dangour AD et al. (2015) Health effects of adopting low greenhouse gas emission diets in the UK. BMJ Open 5, e007364.

55. Macdiarmid JI, Douglas F \& Campbell J (2015) Eating like there's no tomorrow: public awareness of the environmental impact of food and reluctance to eating less meat as part of a sustainable diet. Appetite $\mathbf{9 6}, 487-493$.

56. Garnett T (2014) Three perspectives on sustainable food security: efficiency, demand restraint, food system transformation. What role for life cycle assessment? J Cleaner Prod 73, 10-18. 